\title{
The Portuguese language version of Social Phobia and Anxiety Inventory: analysis of items and internal consistency in a Brazilian sample of 1,014 undergraduate students
}

\author{
Versão para o português do Inventário de Fobia Social e Ansiedade: análise de \\ itens e consistência interna numa amostra de 1.014 estudantes universitários \\ brasileiros
}

Patrícia Picon, Gabriel J. Chittó Gauer, Jandyra M. G. Fachel, Deborah C. Beidel, Ana C. Seganfredo e Gisele G. Manfro

\begin{abstract}
Objective: Theoretical and empirical analysis of items and internal consistency of the Portuguese-language version of Social Phobia and Anxiety Inventory (SPAI-Portuguese). Methods: Social phobia experts conducted a 45-item content analysis of the SPAI-Portuguese administered to a sample of 1,014 university students. Item discrimination was evaluated by Student's $t$ test; interitem, mean and item-to-total correlations, by Pearson coefficient; reliability was estimated by Cronbach's alpha. Results: There was $100 \%$ agreement among experts concerning the 45 items. On the SPAI-Portuguese 43 items were discriminative $(p<0.05)$. A few inter-item correlations between both subscales were below 0.2 . The mean inter-item correlations were: 0.41 on social phobia subscale; 0.32 on agoraphobia subscale and 0.32 on the SPAl-Portuguese. Item-to-total correlations were all higher then $0.3(p<0.001)$. Cronbach's alphas were: 0.95 on the SPAI-Portuguese; 0.96 on social phobia subscale; 0.85 on agoraphobia subscale. Conclusion: The 45 -item content analysis revealed appropriateness concerning the underlying construct of the SPAI-Portuguese (social phobia, agoraphobia) with good discriminative capacity on 43 items. The mean inter-item correlations and reliability coefficients demonstrated the SPAI-Portuguese and subscales internal consistency and multidimensionality. No item was suppressed in the SPAI-Portuguese but the authors suggest that a shortened SPAI, in its different versions, could be an even more useful tool for research settings in social phobia.
\end{abstract}

Key words: social phobia, Social Phobia and Anxiety Inventory (SPAI), internal consistency, reliability.

\begin{abstract}
Resumo
Objetivo: Análise teórica e empírica dos itens e da consistência interna da versão em português do Social Phobia and Anxiety Inventory (SPAIPortuguês) e subescalas. Métodos: Peritos em fobia social conduziram análise de conteúdo dos 45 itens do SPAI-Português, administrado a 1.014 estudantes universitários. A discriminação dos itens foi avaliada por teste $t$ de Student; correlações interitens, médias e item/total por coeficientes de Pearson; fidedignidade pelo alfa de Cronbach. Resultados: Concordância plena entre os peritos para os 45 itens. SPAI-Português com 43 itens discriminativos $(p<0,05)$. Alguns itens, entre as subescalas, apresentaram coeficientes abaixo de 0,2. As médias das correlações interitens foram: 0,41 na subescala fobia social; 0,32 na subescala agorafobia; e 0,32 no SPAI-Português. As correlações item/total foram maiores do que $0,3(p<0,001)$. Alfas de Cronbach foram: 0,95 no SPAI-Português; 0,96 na subescala de fobia social; 0,85 na subescala de agorafobia. Conclusão: 0 conteúdo dos itens foi relacionado aos constructos subjacentes (agorafobia e fobia social), com discriminabilidade de 43 itens do SPAI-Português. As correlações médias interitens e alfas revelaram consistência interna de SPAI-Português e subescalas, além de multidimensionalidade das mesmas. Nenhum item foi suprimido, mas os autores sugerem que uma versão abreviada do SPAI, em suas diferentes versões, seria ferramenta útil para pesquisa em fobia social.

Palavras-chave: fobia social, Inventário de Ansiedade e Fobia Social (SPAI), consistência interna, fidedignidade.
\end{abstract}

Department of Psychiatry and Legal Medicine of Faculdade de Medicina, Pontifícia Universidade Católica do Rio Grande do Sul (FAMED/PUCRS) (Gauer GJC, Picon P, Seganfredo AC)

Department of Statistics, Instituto de Matemática, UFRGS (Fachel JMG)

Department of Psychiatry, Penn State College of Medicine, Pennsylvania, USA (Beidel DC)

Post-Graduation Program in Psychiatry at UFRGS (Manfro GG, Picon P)

Recebido This paper was elaborated from data set of Gabriel J. Chittó Gauer at the Post-graduate Program in

$10-01-06$

Aprovado Psychiatry at UFRGS. Part of the results was presented as posters at the Annual Meeting of the American Psychiatric Association, on May 1-6, 2004, in New York.

Work supported by Fundação de Apoio à Pesquisa do Rio Grande do Sul (FAPERGS; n० 97/50/34.9) and

Fundação de Incentivo à Pesquisa do Hospital de Clínicas de Porto Alegre/UFRGS (FIPE; $n^{\circ} 02.158$ ).

Correspondence to: Patrícia Picon

Rua Padre Chagas, 415/803 - 90570-080 - Porto Alegre-RS - Tel.: (51) 3346-9022 - e-mail: ppicon@terra.com.br 


\section{Introduction}

The Social Phobia and Anxiety Inventory (SPAI) was translated into Portuguese in Brazil (SPAI-Portuguese) by Picon and Gauer (1999) after formal consent of its authors and the publisher Multi-Health Systems. The original English language version (Turner et al., 1996a) was developed by Turner et al. (1989) following the technical standards adopted by the American Psychological Association.

The SPAI is an empirically derived self-report scale for the specific evaluation of social phobia, as per the Diagnostic and Statistical Manual of Mental Diseases (DSM-III) definition, according to the behavior analytic model of scale development. The SPAI takes into account the somatic, behavioral and cognitive dimensions of the social phobia construct (Turner et al., 1996). The SPAI presents 45 items, sub-divided into social phobia and agoraphobia subscales. At the time there were no self-report scales designed to evaluate social anxiety and social phobia, neither for screening nor to assess severity of symptoms based on the Diagnostic and Statistical Manual of Mental Diseases (DSM-III) criteria (Turner et al., 1989; Clark et al., 1997).

American and Canadian social phobia experts helped construct the SPAI, to create and evaluate a pool of items. Studies of three different American samples, one population sample study with social anxiety and two samples of people with social phobia (one population and the other a clinical sample), were performed to reduce the number of items. Each of the remaining items was correlated with the total scale score and those with an item-to-total score correlation coefficient below 0.2 were excluded (Turner et al., 1989; Turner et al., 1996b).

The final version of the SPAI consisted of two subscales: social phobia (items 1 to 32) and agoraphobia (items 33 to 45). Each item has a 7-point Likert format $(0=$ never, to $6=$ always $)$ to evaluate the severity of social anxiety and agoraphobic symptoms. The differential (total) score is obtained by subtracting the social phobia score from the agoraphobia score and has been used as a pure measure of social phobia, discriminating between cases and non-cases of probable social phobia in clinical and non-clinical studies (Beidel, Turner, 1998). The SPAI should not be used alone to confirm definitive diagnosis of social phobia, and it requires complementary clinical evaluation (Turner et al., 1996b).

The SPAI has already been translated into ten languages (Beidel, Turner, 1998) and the psychometric properties of the SPAI-English version and some translated versions have been extensively investigated among adults and adolescents, in population and clinical samples. In these studies the SPAI presented excellent internal consistency with Cronbach's alpha coefficients ranging from 0.91 to 0.95 . On the social phobia subscale that variation was 0.94 to 0.99 , and for the agoraphobia subscale, it was 0.83 to 0.91 (Rush et al., 2000). The exploratory and confirmatory factorial analyses on clinical university students and adolescent American samples and Spanish adolescent samples confirmed the existence of both proposed constructs: social phobia and agoraphobia (Turner et al., 1989 b; Clark et al., 1994; Osman et al., 1995; Osman et al., 1996; Olivares et al., 1999). The SPAl is recommended for individuals aged 14 years and above, with at least sixth-grade reading skills. Compared with other self-report scales to evaluate anxiety and social phobia, the SPAI has an excellent psychometric profile and the average administration time is between 20 to 30 minutes (McNeil et al., 1995; Clark et al., 1997).

For clinical and research purposes, there is a necessity to adapt instruments to the Portuguese language in Brazil to evaluate symptoms of anxiety and social phobia. The validation of the SPAI in Brazilian Portuguese will make it possible to perform screening and severity evaluation of social phobia symptom studies with results comparable to those of other countries.

The validation of the SPAI-Portuguese in Brazilian samples is currently being developed. The results of translation and back-translation, face validity, quantitative linguistic equivalence, feasibility and utility (Picon et al., 2005a) and temporal stability (Picon et al., 2005b) recommend its use as a social phobia screening scale in Brazilian samples with a good level of education, after construct validation studies.

Applying instruments to new populations requires new evaluations of internal consistency. The variability of a latent trait that is being studied in a new population affects this measure (Shrout, 2002).

Within the theoretical framework of classical psychometry, intra-scale reliability is necessary prior to establishing the instrument's construct validity (Pasquali, 1996; Hair et al., 2005). Cronbach's alpha coefficient and mean inter-item correlation coefficient are used to evaluate internal consistency (Shrout 2002; Clark, Watson 1998). The study of the items and of the internal consistency of the SPAI-Portuguese and its subscales is necessary to continue the validation process in Brazilian samples (Streiner, Norman, 1995).

Evaluating items from both a theoretical and empirical perspective addresses their appropriateness regarding the latent traits they propose to represent and their overall utility for the instrument (Pasquali, 1996; Clark, Watson, 1998). The diagnostic measures of internal consistency of multiple Likert scales include the correlations of the items with each other and their means, the correlations of each item with the total scale score, and the estimated reliability (Pasquali, 1996; Hair et al., 2005; Streiner, Norman, 1995; Fachel, Camey, 2000).

The objectives of the present study were to perform: 1) a theoretical analysis of the SPAI-Portuguese and its subscales regarding their content; 2) an empirical analysis of the items examining their distribution, medians, means and standard deviations and their discriminative ability; 3) an internal consistency analysis of the social phobia and agoraphobia subscales and of the SPAI-Portuguese through inter-item, mean inter-item and item-to-total correlations and estimates of reliability evaluated by Cronbach's Alpha coefficient.

\section{Methods}

\section{Sample and procedure}

A sample of 1,014 university students from six different undergraduate courses (347 from Law, 156 from Social Communications, 317 from Civil Engineering, 42 from Languages, 109 from Dentistry and 43 from Social Sciences schools) participated in the study. The mean age was $22.23( \pm 5.43)$ years, without difference between genders $(p=0.116)$, with $520(51.3 \%)$ females and 494 (48.7\%) males. 
The project was approved by the Research Ethics Committee of Pontifícia Universidade Católica do Rio Grande do Sul (PUCRS). Students were invited to participate in the study after finishing their academic activities. They signed the informed consent term following the forms demographic data and SPAI-Portuguese. The students received general instructions to fill out the SPAI-Portuguese. There was no interference of the investigators in their answers. Data confidentiality was guaranteed.

Three social phobia experts, with extensive clinical experience in social phobias, participated in the theoretical analysis of the SPAI-Portuguese items as regards their content, and they were asked to fill out a double entry matrix to classify the 45 items as belonging to one of two categories: social phobia and agoraphobia (Pasquali, 1996; Streiner, Norman, 1995).

\section{Statistical analysis}

The database was developed by an independent double entry dataset and later comparison using the Validate module of Epi Info 6.04d (2001). The statistical analyses were performed using the SPSS 10.0 (SPSS Inc., Chicago; 2000).

The analysis of item contents by the panel of experts was evaluated by rate of concordance (Streiner, Norman, 1995). Using Student's $t$ test for independent samples the discrimination ability of the items was evaluated by comparing the means of answers for each item among $27 \%$ of the participants in the sample with differential (total) lower and higher scores (percentiles 27 and 73) (Pasquali, 1996).

The inter-item correlations and their means, and the item-tototal score correlations of the SPAI-Portuguese and subscales were calculated using Pearson correlation coefficient, which is considered robust even for asymmetrical distribution (Streiner, Norman, 1995). The reliability coefficients were estimated using Cronbach's alpha coefficient (Cortina, 1993).

The following criteria were used in correlation analyses for items performance and internal consistency evaluation: 1 ) inter-item correlations greater than 0.2 are desired and items should correlate more strongly in the subscale to which they belong (Streiner, Norman, 1995; Floyd, Widaman, 1995); 2) mean inter-item correlation at the desired interval of 0.2 to 0.4 and not much greater than 0.5 , i.e., moderate correlation of the items in relation to the constructs (Clark, Watson, 1998); 3) item-to-total correlation, omitting one item at a time, greater than 0.3 for item maintenance and values below 0.2 as an indication of a non-existent correlation with the underlying construct (Clark, Watson, 1998); 4) Cronbach's alpha coefficient values, eliminating one item at a time, check the items that, when removed, will significantly increase the value of alpha for that scale; 5) Cronbach's alpha coefficient minimum value of 0.8 for scale's reliability estimate (Clark, Watson, 1998; Streiner, Norman, 1995; Cortina, 1993; Fachel, Camey, 2000).

\section{Results}

\section{Item level analysis}

The rate of agreement among the three experts on the 45 items of the Portuguese language SPAI in the double entry matrix was $100 \%$, i.e., there were no differences in the categorizations of items related to social phobia and agoraphobia constructs.

The 45-item descriptive analyses showed an asymmetrical distribution of all of them (Kolmogorov-Smirnov; $p<0.0001$ ).
The 45-item median scores of the SPAI-Portuguese and social phobia subscale ranged from 0 to 4 and for the agoraphobia subscale items ranged from 0 to 3 . The item mean of the SPAIPortuguese was $1.81 \pm 0.95$ to 1.86 . The item mean on social phobia subscale was $2.03 \pm 1.08$ to 1.6. In the agoraphobia subscale, the item mean was $1.25 \pm 0.95$ to 1.86 .

The 45-item discrimination ability was significant in 41 of the 45 items $(p<0.05)$. There was no difference on the means for the differential (total) score of items $33,40,41$ and 43 at the percentile 27 compared with percentile $73(p>0.05)$. These items belong to the agoraphobia sub-scale.

\section{Internal consistency}

The inter-item correlations did not present any negative results on the subscales or in the SPAI-Portuguese. In the SPAIPortuguese the inter-item correlations varied from 0.04 to 0.84 . These correlations were inferior to 0.2 only between several items of social phobia subscale and agoraphobia subscale. The interitem correlations between items 1 to 32 and 33 to 45 were higher, respectively, in the social phobia and agoraphobia subscales.

On the social phobia subscale the inter-item correlations varied from 0.20 to 0.84 , with correlations below 0.3 only between item 21 and ten other items of the subscale.

On the agoraphobia subscale, the inter-item correlations varied from 0.14 to 0.59 , with correlations below 0.2 only between item 43 and seven other items on the subscale.

The social phobia subscale presented three pairs of items that are strongly correlated, with $r>0.7$ (Table 1).

Table 1. Subscale of social phobia: item pairs with strong correlations

\begin{tabular}{lc}
\hline Pairs of items & $r$ \\
\hline 9 and 10 & 0.8 \\
24 and 25 & 0.72 \\
31 and 32 & 0.84 \\
\hline
\end{tabular}

$r=$ Pearson correlation coefficient; $p<0.001$ for each item pair.

The mean inter-item correlations for the social phobia and agoraphobia subscales were 0.41 and 0.32 , respectively, and for the SPAI-Portuguese was 0.32 .

The item-to-total score correlations varied from 0.31 to 0.73 in the SPAI-Portuguese. On the social phobia and agoraphobia subscales the item-to-total score correlations varied respectively from 0.47 to 0.76 and from 0.33 to 0.6 . All mentioned item-to-total score correlations reached a level of significance for $p<0.0001$.

Cronbach's alpha coefficients presented the following results: SPAI-Portuguese, $\alpha=0.95$; social phobia subscale, $\alpha=$ 0.96; and agoraphobia subscale, $\alpha=0.85$ (Table 2). When all items on the two subscales and in the SPAI-Portuguese were removed, one by one, Cronbach's alpha coefficient values did not present any relevant modifications.

\section{Discussion}

\section{Item level analysis}

The rate of concordance among the experts concerning all SPAI-Portuguese items showed that there was no difference 
Table 2. Internal consistency studies of the Social Phobia and Anxiety Inventory (SPAl), social phobia (SP) and agoraphobia (AG) subscales in different language versions

\begin{tabular}{|c|c|c|c|c|c|c|}
\hline Study & Type of sample & $n$ & Age (years) & $\alpha$ SPAI & $\alpha$ SP & $\alpha A G$ \\
\hline Turner et al., 1989 (English, USA) & Students & 308 & 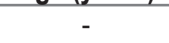 & - & 0.96 & 0.85 \\
\hline Clark et al., 1994 (English, USA) & Adolescents & 223 & 12 to 18 & 0.97 & 0.97 & 0.91 \\
\hline Osman et al., 1996 (English, USA) & Students community & $\begin{array}{l}236 \\
150\end{array}$ & $\begin{array}{c}22.1( \pm 2.6) \\
37.1( \pm 11.3)\end{array}$ & - & $\begin{array}{l}0.96 \\
0.94\end{array}$ & $\begin{array}{l}0.86 \\
0.83\end{array}$ \\
\hline Böegels \& Reith, 1999 (Dutch, Holland) & Clinical & 157 & $32.5( \pm 10,4)$ & - & 0.99 & 0.91 \\
\hline Olivares et al., 1999 (Spanish, Spain) & Adolescents & 3,160 & $15.2( \pm 0.9)$ & 0.95 & 0.95 & 0.84 \\
\hline Picon et al., 2005 (Portuguese, Brazil) & University students & 1,014 & $22.2( \pm 5.3)$ & 0.95 & 0.96 & 0.85 \\
\hline
\end{tabular}

$\alpha$ : Cronbach's alpha coefficient.

in their judgments on items appropriateness concerning social phobia and agoraphobia constructs. The results strongly suggest that the translation and back-translation process preserved the content validity of the original SPAI as well as its goal to evaluate two different constructs (social phobia and agoraphobia). The high rate of concordance was used as criterion on the appropriateness of items regarding the SPAI-Portuguese constructs, and the decision to maintain all 45 items. The finding supports the content validity of the Brazilian Portuguese language inventory (Pasquali, 1996; Streiner, Norman, 1995).

The descriptive analyses showed a positively asymmetric distribution of 43 of the 45 items, what agrees with the absence of social anxiety or agoraphobia among the majority of the study participants. The items that presented a negative asymmetry were items 3 (concerning anxiety when the individual is the center of attention) and 5 (concerning anxiety when the individual has to speak to an audience). These findings indicate a differentiated prevalence of latent trait measures by these items in a population of university students who are often asked to perform academic tasks that require social exposure.

The inclusion of zero values among the medians of the items suggest their low discrimination ability, and would mean that at least $50 \%$ of the sample answered zero (never) for those items. However, this was expected, since the population sample consisted primarily of participants with no social phobia or agoraphobia disorders.

The 45-item means revealed no adherence to low discriminative values in any of the items taken singly, since they are not excessively close to the extreme values $(0$ to 6$)$. The variability of SPAI-Portuguese items suggests some homogeneity in the dispersion evaluated by the standard deviation, and especially for the social phobia subscale that varied from 1.08 to 1.6. So far the results described suggest a good discrimination ability of the items (Clark, Watson, 1998).

According to the classical psychometric theory, only four items were not discriminatory, in the sense of differentiating subjects with different magnitudes of the latent trait for which that item is the behavioral representation (Pasquali, 1996). These were the agoraphobia subscale items $33,40,41$ and 43 which refer to: anxiety at being alone at home, in high places, in a very long queue and the need to go out of the house in company of a family member or friend when going to several places.

\section{Internal consistency}

The majority of the inter-item correlations in the social phobia and agoraphobia subscales were moderate, revealing co-linearity among them. The finding is desirable, since it reveals the inter- correlation of items related to the constructs that they represent. Lower values would lead to poor item performance in future factorial analyses (Floyd, Widaman, 1995).

The low inter-item correlations on the subscales of social phobia and agoraphobia denoted the different constructs to which these items refer, since the inter-item correlations should be greater on the scales in which items are theoretically pertinent. The findings demonstrated the existence in the SPAI-Portuguese of the two subscales conceptually proposed in the original version.

Items 21 and 43 have the lowest inter-item correlations on the scale they belong. Item 43 refers to the need to go out accompanied; item 21 refers to the anxiety of writing or typing in front of other people. Prior to eliminating items with low correlations, it is prudent to consider why that might happen. Items refer to the still well established agoraphobic and social anxiety constructs (APA, 1994). The subscales should evaluate more than one dimension of the constructs they represent, so weaker inter-item correlations can be found. Another plausible explanation for the bad performance of items 21 and 43 on their subscales would be the composition of the sample, in which the need to go out in company, and the presence of anxiety when writing or typing in public would make it impossible to carry out an academic routine. These items should be studied in a clinical sample (Streiner, Norman, 1995).

Although items that present a high co-linearity may cause an internal consistency overestimation, maintaining them would be clinically relevant (Hair et al. 2005; Clark, Watson, 1998). For example, pair 9 and 10 refers to anxiety in small and large gatherings. It is useful to consider that individuals who endorse anxiety in small gatherings will present it also in large ones, what would justify its strong correlation. Pair 24 and 25 evaluates the same latent trait: avoidance of social situations. However, they evaluate different levels of avoidance, and they refer to the attempt to avoid social situations and to abandon social situations because they are anxiety provoking. In pair 31 and 32, the items refer to physical symptoms of anxiety before and during a social situation. These items may in fact reflect very similar aspects of the somatic dimension of social anxiety, which includes anticipatory anxiety aspects. However literature emphasizes a major variability regarding number and type of symptoms presented by individuals that have a social phobia, which arise in very different social situations (Hoffmann et al., 2004). The SPAI was not developed exclusively for the purpose of screening, but also to quantify severity of symptoms, and to follow up therapeutic interventions (Turner et al., 1996b). Thus, the authors decided to maintain all the items discussed here, in order to avoid loss of content validity of the SPAI-Portuguese compared to the original version. 
Considering the results in the studied sample, items with strong correlations should be taken into account in case the SPAI authors decide to review the instrument at a later date. A shorter version would diminish the administration time, and it appears desirable, as long as no loss of content and construct validity occurs (Marshall, Nelson, 2000). The appropriate reduction of the number of items in both subscales would result in a valid substitute SPAI shortened version. It could be of great convenience and especially useful for research settings. The results of the Brazilian study support the recommendation made by the authors of the Dutch language version of SPAI, that a shorter version should be developed, based on their analyses of internal consistency (Bögels et al., 1999). The original authors are currently working on a shorter version of the SPAI English version (Beidel, personal communication 2005).

Internal consistency is a function of two parameters: the number of items on the scale and the mean inter-item correlation (Clark, Watson, 1998). The acceptable limit for values of alpha is higher, the number of items is greater and high values are expected when one has scales with over 40 items (Hair et al., 2005).

The estimates of reliability in the subscales and in the SPAI-Portuguese indicate excellent indexes, all of them above the desired level, showing a high degree of internal consistency. Alpha coefficients are comparable to those found in several studies of American, Spanish and Dutch samples (Table 2) (Turner et al., 1989a; Clark et al., 1994; Osman et al., 1995; Osman et al., 1996; Olivares et al., 1999; Bögels et al., 1999).

One of the most used methods to evaluate the homogeneity of a scale, considered one of the bases of its internal consistency, is the item-to-total correlation. Its goal is to have a scale that is homogeneous, i.e., capable of evaluating different aspects of a same construct, not traits of other constructs. The results revealed significant item-to-total score correlations, always above 0.3 on each subscale and in the SPAI-Portuguese (Fachel, Camey, 2000). Cronbach's alpha coefficient values did not vary with the statistical elimination of items one by one, i.e., the items taken singly did not substantially modify the internal consistency of the scale, evaluated by this coefficient. This analysis did not reveal any item to be eliminated (Hair et al., 2005).

On the social phobia and agoraphobia subscales, the number of items is not excessive (Clark, Watson, 1998) and the values of Cronbach's alpha coefficients should be considered as measures of excellent reliability. In the SPAI-Portuguese the very high value of Cronbach's alpha coefficients could be related to the number of items and to the presence of a strong correlation between some of them. This assumption supports the proposal to reduce the number of items of the SPAI.

Items that presented a lower performance and would be candidates for elimination in a short version are: on the social phobia subscale, item 21 and one item from each pair with strongest correlations; on the agoraphobia subscale, items 33 , 40, 41 and 43.

The mean inter-item correlations for the social phobia and agoraphobia subscales and for the SPAI-Portuguese were moderate and perfectly acceptable. The mean interitem correlation may be a more useful measure of internal consistency than the Cronbach's alpha coefficient per se, especially with a great number of items (Streiner, Norman, 1995; Cortina, 1993). However, the isolated mean inter-item correlations do not revel the scale unidimensionality. All interitem correlations should fall in the range of $0.15-0.5$ and be grouped around the mean inter-item correlation to ensure the scale unidimensionality (Clark, Watson, 1998).

There is a certain amount of confusion in literature on the concept of internal consistency, which refers to the degree of interrelationships between the items of a scale and the concept of homogeneity, when it refers more specifically to unidimensionality, i.e., how homogeneously the items of a scale evaluate a single dimension or underlying construct (Clark, Watson, 1998; Cortina, 1993). Scales developed from theoretical concepts such as the SPAI are more internally consistent (Streiner, Norman, 1995). The high levels of Cronbach's alpha coefficient are necessary, but they are not sufficient to prove homogeneity as an equivalence of unidimensionality of the scales. The internal consistency estimated by Cronbach's alpha coefficient is not exactly the same as homogeneity or unidimensionality, since it does not ensure that items will be a unidimensional representation of a construct (Pasquali, 1996). A set of items may be internally consistent and multidimensional (Cortina, 1993). The mean inter-item correlations on each subscale and in the SPAI-Portuguese, which are all inferior to the values of alpha coefficients, reveal that the items of the inventory are not related to a single construct, and that the items on each subscale do not belong to a single dimension of the underlying construct.

The results demonstrated that the SPAI-Portuguese has at least two different constructs, as was the intention in the original English version.

\section{Conclusion}

The analysis of item content revealed their pertinence to the constructs of social phobia and agoraphobia underlying the SPAI. The items of the SPAI-Portuguese were mostly discriminatory. In the social phobia subscale all items were discriminatory. The results support maintaining the items of the SPAI-Portuguese, and especially the items of the social phobia subscale.

In the studied sample, inter-item and item-to-total correlation analyses indicate the item's appropriateness as related to their constructs, and justify it including all of them in future factorial analyses. Inter-item means and reliability results showed excellent levels of internal consistency of the social phobia and agoraphobia subscales, as well as on the SPAIPortuguese. These results suggest that the items reflect their constructs, preserved in the translation and back-translation process to the Portuguese language as spoken in Brazil.

The suppression of items at this point in the Brazilian validation process would lead to a loss of content validity as regards the representation of all dimensions of the constructs that the inventory intends to validate. Further studies in Brazilian and other culture populations are needed in order to look at how items behave. At this time, no items that should be eliminated were detected, but results indicate a few that might be candidates for suppression in a shortened version of the SPAI. 
A shortened version might be especially useful internationally to screen probable cases of social phobia in research settings. The results are useful for a future review of the SPAI.

The mean inter-item correlations strongly suggest the multidimensionality on both subscales to be confirmed in factorial analyses. The finding agrees with the SPAl objective of evaluating the cognitive, somatic and behavioral dimensions of the social phobia construct. It also evaluates the presence of agoraphobic anxieties in their different dimensions, within the cognitivebehavioral psychology theoretical referential in which the instrument was originality developed.

The results of the present study support the appropriateness of the SPAI-Portuguese as an instrument to screen and evaluate anxiety and social phobia in Brazilian samples, especially after studies of construct validity.

\section{Acknowledgments}

To Norberto L.C. Martins, M.D., for his collaboration in structuring the database and programming the calculation of computerized scores. To Professor Eliane Falcone, Ph.D., from Universidade Federal do Rio de Janeiro (UFRJ), Professor Mauro Terra, M.D., Ph.D., from Fundação Faculdade Federal de Ciências Médicas de Porto Alegre, and Rogéria Recondo, M.D., M.Sc., from PUCRS, for their collaboration in the content analysis of the SPAI-Portuguese.

\section{References}

American Psychiatric Association. Diagnostic and Statistical Manual of Mental Disorders: DSM-IV. $4^{\text {th }}$ ed. Washington (DC): American Psychiatric Association; 1994.

Beidel DC, Turner SM. Shy children, phobic adults: nature and treatment of social phobia. Washington (DC): American Psychological Association; 1998.

Bögels SM, Reith W. Validity of two questionnaires to assess social fears: the Dutch Social Phobia and Anxiety Inventory and the Blushing, Trembling and Sweating Questionnaire. J Psychopathol Behav Assess, 21: 51-66, 1999.

Clark DB, Feske U, Masia CL, Spaulding SA, Brown C, Mammen O, Shear MK. Systematic assessment of social phobia in clinical practice. Depress Anxiety, 6: 47-61, 1997.

Clark DB, Turner SM, Beidel DC, Donovan JE, Kirisci L, Jacob RG. Reliability and validity of the Social Phobia and Anxiety Inventory for adolescents. Psychol Assess, 6: 135-40, 1994.

Clark LA, Watson D. Constructing validity: basic issues in objective scale development. In: Kazdin AE. Methodological issues and strategies in clinical research. $2^{\text {nd }}$ ed. American Psychological Association, $p$. 215-39, Washington (DC), 1998.

Cortina JM. What is coefficient Alpha? An examination of theory and applications. Appl Psychol, 78: 98-104, 1993.

Fachel JMG, Camey S. Avaliação psicométrica: a qualidade das medidas e 0 entendimento dos dados. In: Cunha JA, organizador. Psicodiagnóstico. 5 ed. Artmed, p. 158-70, Porto Alegre, 2000.

Floyd FJ, Widaman KF. Factor analysis in the development and refinement of clinical assessment instruments. Psychol Assess, 7: 286-99, 1995.

Hair JF, Anderson RE, Tatham RL, Black WC. Análise multivariada de dados. 5 ed. São Paulo: Bookman; 2005.

Hoffmann SG, Heinrichs N, Moscovitch DA. The nature and expression of social phobia: toward a new classification. Clin Psychol Rev, 24: 769-97, 2004

Marshall S, Nelson LD. Clinical and research implications of revising psychological tests. Psychol Assess, 12: 298-303, 2000.

McNeil DW, Ries BJ, Turk CL. Behavioral assessment: self-report, physiology, and overt behavior. In: Heimberg RG, Liebowitz MR, Hope DA, Schneier FR, editors. Social phobia: diagnosis, assessment, and treatment. The Guilford Press, p. 202-31, New York, 1995.

Olivares J, García-Lopez LJ, Hidalgo MD, Turner SM, Beidel DC. The Social Phobia and Anxiety Inventory: reliability and validity in an adolescent Spanish population. J Psychopathol Behav Assess, 21: 67-79, 1999.

Osman A, Barrios FX, Aukes D, Haupt D, King K, Osman JR, Slavens S. The Social Phobia and Anxiety Inventory: further validation in two nonclinical samples. J Psychopathol Behav Assess, 18: 35-47, 1996.

Osman A, Barrios FX, Aukes D, Osman JR. Psychometric evaluation of the Social Phobia and Anxiety Inventory in college students. J Clin Psychol, 51: 235-43, 1995.

Pasquali L, organizador. Teoria e métodos de medida em ciências do comportamento. Brasília: INEP; 1996.

Picon P, Gauer GJC, Fachel JMG, Manfro GG. Desenvolvimento da versão em português do Social Phobia and Anxiety Inventory (SPAI). Revista de Psiquiatria do Rio Grande do Sul, 27: 40-50, 2005a.

Picon P, Gauer GJC, Hirakata VN, Haggsträm LM, Beidel DC, Turner SM, Manfro GG. Fidedignidade da versão em português do Inventário de Ansiedade e Fobia Social (SPAl) em amostra heterogênea de estudantes universitários brasileiros. Revista Brasileira de Psiquiatria, 27: 124-30, 2005b.

Rush AJ, Pincus HA, First MB, Blacker D, Endicott J, Keith SJ. Handbook of psychiatric measures: Task Force for the Handbook of Psychiatric Measures. Washington (DC): American Psychiatric Association; 2000.

Shrout PE. Reliability. In: Tsuang MT, Tohen M, editors. Textbook in psychiatric epidemiology. $2^{\text {nd }}$ ed. New York: Wiley-Liss; 2002.

Streiner DL, Norman GR. Health measurement scales: a practical guide to their development and use. $2^{\text {nd }}$ ed. London: Oxford University Press; 1995.

Turner SM, Beidel DC, Dancu CV. SPAI: Social Phobia and Anxiety Inventory: Manual. North Tonawanda (NY): Multi-Health Systems; 1996b.

Turner SM, Beidel DC, Dancu CV, Stanley MA. An empirically derived inventory to measure social fears and anxiety: the Social Phobia and Anxiety Inventory. Psychol Assess, 1: 35-40, 1989a.

Turner SM, Dancu CV, Beidel DC. SPAI: Social Phobia and Anxiety Inventory: Inventory. North Tonawanda (NY): Multi-Health Systems; 1996a.

Turner SM, Dancu CV, Beidel DC. SPAl: Social Phobia and Anxiety Inventory: Inventory. Translated into Portuguese by Picon P, Gauer GJC. North Tonawanda (NY): Multi-Health Systems; 1999.

Turner SM, Stanley MA, Beidel DC, Bond L. The Social Phobia and Anxiety Inventory: construct validity. J Psychopathol Behav Assess, 11: 221-34, 1989 b. 